\title{
Biopolítica en el Mundo Contemporáneo
}

\section{Biopolitics in the Modern World}

$\begin{array}{ll}\text { Nombre: } & \text { Carlos Miranda Rozas ( }{ }^{1} \text { ) } \\ \text { Filiación: } & \text { Pontificia Universidad Católica de } \\ & \text { Valparaíso } \\ \text { País: } & \text { Chile } \\ \text { Correo: } & \text { camarraz@yaho.es }\end{array}$

\section{RESUMEN}

Resumen: El siguiente ensayo busca presentar algunas de las ideas centrales que Foucault y Agamben desarrollaron en torno al concepto de biopolítica, ya que dicho concepto nos permite entender y analizar fenómenos sociales contemporáneos, en donde el elemento común es la intervención sobre el cuerpo de las personas. Para ello se expondrán parte de las ideas de los citados autores, para finalmente identificar algunas líneas de investigación en los ámbitos en donde las ideas revisadas poseen un potencial interpretativo y explicativo importante, pero también permiten cuestionar algunos aspectos del orden social vigente en el cual la tendencia a la intervención directa sobre el cuerpo se hace cada vez más frecuente, dejando de la lado los ideales democráticos y legitimando la inequidades del sistema social.

\section{ABSTRACT}

The following essay seeks to present some of the central ideas that Foucault and Agamben developed around the concept of biopolitics, since this concept allows us to understand and analyze contemporary social phenomena, where the common element is the intervention of people's bodies. In order to achieve this some ideas of these authors will be exposed, and some to finally identify some lines of research in the areas in which these ideas have an important interpretive and explanatory potential, but also allow to question some aspects of the social order in which the tendency to direct body interventions becomes increasingly common, leaving democratic ideals on the side and legitimizing the inequities of the social system.

\footnotetext{
1 El autor es Licenciado en Sociología, y actualmente realiza el Magister en Historia en la Pontificia Universidad Católica de Valparaíso. Su línea de investigación es la historia contemporánea.
} 


\section{SEe}

PALABRAS CLAVES: Biopolítica, población, medicalización, estado de excepción, campo de concentración.

KEYWORDS: Biopolitics, population, medicalization, comprehensive review, concentration camp.

\section{Introducción}

En la entrevista que el historiador Gabriel Salazar le hizo a Carlos Altamirano el año 2010, éste último decía que para la derecha chilena, los militantes de partidos de izquierda carecían de derechos cívicos y humanos, y por lo tanto eran técnicamente torturables y masacrables, sin que ello contraviniera ninguna ley (Salazar, 2010). Asimismo, durante el año 2005 se filtró a la prensa que la CIA mantenía, desde el año 2001, con el acuerdo de la OTAN (http://www.webislam.com), cárceles secretas, fuera de toda normativa legal, en Polonia y Rumanía, para recluir a sospechosos de terrorismo, apresados fundamentalmente en Irak y Afganistán. Se señaló que en dichas cárceles se practicaban torturas a los prisioneros, a los que no se les levantaba ningún tipo de cargo ni se les respetaba derecho alguno; es decir, estaban totalmente expuestos e indefensos frente a las decisiones de sus captores. En este mismo sentido puede agregarse la prisión de Guantánamo y la muerte de Osama Bin Laden, a manos de fuerzas especializadas de los Estados Unidos, sin lectura de cargos, sin proceso, sin abogado defensor, etc.

Por otra parte, en las últimas décadas se ha producido un enorme despliegue de campañas publicitarias destinadas a informar y educar a la población en temas de salud, con el fin de disminuir conductas de riesgo y las probabilidades de contraer algunas de las enfermedades sobre las que se está informando. Desde la década de 1980, múltiples campañas publicitarias han informado y promovido conductas preventivas del contagio del VIH-Sida y, más recientemente, se han desplegado campañas para prevenir la propagación de la pandemia causada por el virus AH1N1. Asimismo, año a año, se suceden campañas para incentivar a la población a dejar de fumar, a cuidarse de los riesgos de la exposición al sol, etc., todo ello con el objetivo de prevenir diversos tipos de cáncer.

La magnitud de las campañas es tal que, solo en España, el Consejo General de Colegios Oficiales de Farmacéuticos, realizó entre el 2002 y 2008, 65 campañas destinadas a informar e incentivar a la población a desarrollar conductas autoprotectoras de su salud (http://www.portalfarma.com).

Todos estos hechos pueden entenderse como ejemplos concretos de la acción biopolítica, fenómeno que según Foucault es característico de la forma liberal de gobernar desde su aparición hacia mediados del siglo XVIII. Para entender esos y otros hechos similares, se considera importante estudiar en qué consiste 


\section{SEe}

precisamente el fenómeno biopolítico y cómo se ha presentado durante los últimos dos siglos.

\section{El fenómeno de la Biopolítica}

El concepto de biopolítica se asocia generalmente a la obra de Michel Foucault ${ }^{2}$, quien lo utilizó hacia mediados de la década de 1970 en su obra "Historia de la Sexualidad" y en las conferencias que dictó en el Collège de France, en las que el tema central consistía en los diversos procesos, prácticas y mecanismos que los gobiernos europeo-occidentales comenzaron a desplegar a partir del siglo XVIII para intervenir sobre los procesos asociados con la vida de las poblaciones. A este abordamiento político de la vida Foucault lo llamó biopolítica.

Para Foucault, esta nueva preocupación de los gobiernos se debió a que reconocieron que "no tienen que vérselas con individuos simplemente, ni siquiera con un "pueblo", sino con una "población" y sus fenómenos específicos" (Foucault, 1998: 17) como lo son su distribución geográfica, sus niveles de natalidad o de mortalidad así como de morbilidad, sus enfermedades más frecuentes, los problemas de la vejez, etc., ya que si se quiere gobernar a las poblaciones se hace necesario conocerlas para intentar regular su variación y aleatoriedad (Castro, 2007), debido a que esta aleatoriedad puede representar un peligro para el orden social que el nuevo arte liberal de gobernar se esfuerza por preservar.

En este contexto, los procesos de medicalización tuvieron por objeto administrar los peligros aleatorios inherentes a una comunidad de seres vivos. Esto explicaría, a juicio de Foucault, la aparición durante el siglo XIX de todo un despliegue destinado a educar a la población en relación con los peligros a los que está expuesta. En este sentido señala Foucault: "véanse todas las campañas relacionadas con la salud y la higiene; miren todo lo que pasa en torno a la sexualidad y del miedo a la degeneración: degeneración del individuo, de la familia, de la raza, de la especie humana. Por último vemos en todas partes esa estimulación del temor al peligro" (Foucault, 2006: 93 - 102).

Este proceso de medicalización tendiente a controlar los eventos riesgosos que puedan producirse en una masa viviente, comenzó a gestarse, según Foucault, a fines del siglo XVIII e incluye tres procesos consecutivos ocurridos en Alemania, Francia e Inglaterra.

\footnotetext{
${ }^{2}$ El pensador francés no fue el primero en utilizar dicho término; de hecho, el doctor Edgardo Castro de la Universidad de San Martín, Argentina, afirma que el concepto se remonta al sueco Rudolf Kyellen, quien con la utilización del concepto, hacia 1905 " hace referencia a una concepción de la sociedad, del estado y de la política en términos biológicos y, más precisamente, patológicos: el estado es una realidad biológica, un organismo, y, puesto que este organismo vive en un continuo desorden, la política tiene que basarse en la patología". (Castro, 2007: 2)
} 


\section{SEe}

En Alemania se formó, en primer lugar, una medicina del Estado: "No es el cuerpo del trabajador lo que interesa a esa administración estatal de salud, sino el propio cuerpo de los individuos que en su conjunto constituyen el Estado" (Foucault, 1996: 92).

Posteriormente, en Francia aparece, antes de la revolución, la medicina urbana que se centrará en el concepto de salubridad: "Salubridad $e$ insalubridad significan el estado de las cosas y del medio en cuanto afectan a la salud; la higiene pública es el control político-científico de este medio" (Foucault, 1996: 100).

Por último, en Inglaterra se desarrollará la tercera dirección de este proceso que se centrará en los pobres, en la fuerza laboral, en los obreros. El problema de los pobres y los trabajadores se hizo patente en el segundo tercio del siglo XIX, por varias razones:

$1^{a}$. Durante la Revolución Francesa y en Inglaterra, durante las grandes agitaciones de comienzos del siglo XIX, la población necesitada se convierte en una fuerza política capaz de rebelarse o por lo menos de participar en las revueltas.

$2^{\mathrm{a}}$. En el siglo XIX se encontró un medio que sustituía en parte los servicios prestados por la población, como el establecimiento, por ejemplo, de un sistema postal y un sistema de cargadores, lo que provocó una serie de disturbios populares en protesta por esos sistemas que privaban del pan y de la posibilidad de vivir a los más pobres.

$3^{a}$. Con la epidemia de cólera de 1832 , que comenzó en París y se propagó a toda Europa, cristalizaron una serie de temores políticos y sanitarios con respecto a la población proletaria o plebeya. A partir de esa época, se decidió dividir el recinto urbano en sectores pobres y ricos. Se consideró que la convivencia de pobres y ricos en un medio urbano entrelazado constituía un peligro sanitario y político para la ciudad (Foucault, 1996: 102).

Todos estos hechos hicieron de los pobres un peligro y por ello esta medicina "consiste esencialmente en un control de la salud y del cuerpo de las clases más necesitadas, para que fueran más aptas para el trabajo y menos peligrosas para las clases adineradas" (Foucault, 1996: 105). En consecuencia, se desplegaron iniciativas de vacunación, se llevó un registro médico de los pobres, se identificaron los focos de insalubridad, se dividió la ciudad entre ricos y pobres, todo ello con el objeto de prevenir las amenazas que éstos representaban.

Como se puede apreciar, la medicina administra con sus métodos los peligros de la población, pero esto no se limita al terreno de las prácticas, ya que detrás de ellas hay todo un entramado discursivo teórico que ve en los problemas sociales (hacinamiento obrero, plagas, etc.) solo un problema médico y que, por lo tanto, 


\section{SEe}

debe ser abordado con los métodos de la medicina, es decir, interviniendo sobre el cuerpo de las personas y no abordando los procesos sociales que generan dichas enfermedades (industrialización sin regulación, urbanización acelerada, etc.). Por todo ello la medicalización no solo permite defenderse de los peligros de la población, por sus métodos, sino que también permite legitimar las desigualdades, propias del orden social, al definir problemas sociales solamente como problemas médicos. La medicalización constituye, por tanto, un proceso biopolítico esencial, ya que ella permitirá conocer y administrar los peligros de la población y legitimar el orden social.

Este proceso de medicalización se presentó en las sociedades del siglo XIX a ambos lados del Atlántico, con algunas décadas de diferencia, pero fue común en las últimas décadas del siglo, cuando los problemas ligados a la urbanización y la proletarización, ambos efectos del desarrollo capitalista, hicieran sentir a las clases dominantes que era necesario protegerse de la amenaza que representaban los pobres: amenaza fisiológica (transmisión de enfermedades), amenaza a la raza (herencia degenerada), amenaza a la moral (alcoholismo, prostitución), amenaza a la propiedad (delincuencia), amenaza al orden social (anarquismo y comunismo).

Es preciso destacar aquí que todo este despliegue de actuaciones sobre la vida de las poblaciones fue posible gracias al desarrollo previo de las técnicas disciplinarias o conjunto de reglamentos militares, hospitalarios, escolares, etc., destinados a controlar y corregir los movimientos del cuerpo, logrando con ello aumentar sus fuerzas en términos económicos y disminuirlas en términos políticos de obediencia (Foucault, 1987). Estas técnicas disciplinarias desarrolladas a partir del siglo XVII, fueron fundamentales para el posterior desarrollo capitalista ya que

"el capitalismo, que se desenvuelve a fines del siglo xviii y comienzos del xix, socializó un primer objeto, que fue el cuerpo, en función de la fuerza productiva, de la fuerza laboral. El control de la sociedad sobre los individuos no se opera simplemente por la conciencia o por la ideología sino que se ejerce en el cuerpo, con el cuerpo. Para la sociedad capitalista lo importante era lo biológico, lo somático, lo corporal antes que nada" (Foucault, 1996: 87).

Disciplinar el cuerpo y regular la población, he ahí las dos formas en torno a las cuales se desarrolló la organización del poder sobre la vida, lo que permitió hacerla, según Foucault, funcional al desarrollo del capitalismo: "Ese bio-poder fue, a no dudarlo, un elemento indispensable en el desarrollo del capitalismo; éste no pudo afirmarse sino al precio de la inserción controlada de los cuerpos en el aparato de producción y mediante un ajuste de los fenómenos de población a los procesos económicos" (Foucault, 1996: 84) y sería precisamente ésta una de las consecuencias 


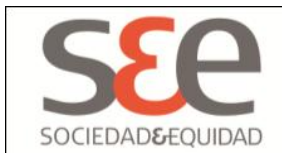

esenciales de la biopolítica, esto es, contribuir a través de la regulación, protección y potenciación de la vida, al mantenimiento y expansión del capitalismo.

Otro desarrollo importante del concepto de biopolítica se encuentra en el filósofo italiano, Giorgio Agamben, para quien la biopolítica es un componente esencial de la política occidental desde sus orígenes. Esta idea la fundamenta haciendo un análisis de concepciones políticas y jurídicas griegas y romanas donde lo central es el concepto de estado de excepción.

Agamben señala que los griegos establecieron una diferencia entre vida natural o nuda vida (zôe), la vida solo remitida a su aspecto biológico y la vida en la polis. La primera permanece excluida de la polis, restringida a la esfera privada del oikos (Berrío, 2010). De este modo "la existencia de la política está determinada por la exclusión de la vida natural (zôe) que, a su vez, está asociada, desde Aristóteles, a la idea misma de humanidad" (Berrío, 2010: 21).

Sin embargo, para Agamben esta exclusión de la vida natural o nuda vida, es en realidad una forma particular de inclusión, ya que esta existencia que está fuera de la comunidad política, fuera de la ley, queda por lo tanto completamente a merced del soberano; es una vida con la cual el soberano puede disponer lo que sea, porque en ella la ley no se aplica, no está bajo el amparo de la ley. La nuda vida está, entonces, según Agamben, en un estado de excepción. Este estado de excepción Agamben lo remonta al derecho romano con la figura del hombre sagrado (Berrío, 2010):

Aquél a quien el pueblo ha juzgado por un delito; no es lícito sacrificarle, pero quien le mate, no será condenado por homicidio. En efecto, en la primera ley tribunicia se advierte que "si alguien mata a aquel que es sagrado por plebiscito, no será condenado por homicida"... De ahí viene que se suela llamar sagrado a un hombre malo e impuro... a quien cualquiera podía matar impunemente, y no debía, sin embargo, recibir la muerte en las formas sancionadas por el rito (Berrío, 2010:24).

Al ser excluido de la muerte conforme al rito, pero pudiendo ser asesinado por cualquiera, el hombre sagrado queda así, fuera, tanto del derecho humano como del divino. En el hombre sagrado la ley no se aplica, quedando así a disposición de cualquiera; cualquiera puede matarle, su vida está constantemente en estado de excepción.

Este estado de excepción, sin embargo, no constituye para Agamben una alteración del orden normal en la vida política, sino que por el contrario, dicha excepcionalidad es la norma de la política en tanto que la vida desnuda o vida 


\section{SEe}

despojada de derechos, ha estado en el centro del poder soberano desde la antigüedad. La excepción no es un fenómeno anómalo de este poder sino un fundamento de su normalidad, ya que lo que define al soberano es justamente esta capacidad para disponer de la nuda vida (Múnera y Benavides, 2008).

Para Agamben el ejemplo paradigmático del estado de excepción es el campo de concentración. El autor citado define el campo como "el espacio que se abre cuando el estado de excepción comienza a devenir la regla. En ese momento, el estado de excepción, que era esencialmente una suspensión temporal del ordenamiento, adquiere un orden especial permanente que, como tal, permanece, sin embargo, constantemente fuera del ordenamiento normal" (Agamben, 1998: 4). En el campo el estado de excepción es lo normal, por ello sus "habitantes" están permanentemente fuera de la ley, están siempre expuestos como vida natural a las disposiciones del soberano; la excepción se realiza de forma estable. Esta situación lleva a afirmar a Agamben que el campo de concentración "en tanto sus habitantes están desprovistos de todo estatuto político y reducidos integralmente a una vida desnuda, el campo es también el más absoluto espacio biopolítico que jamás se haya realizado, en el cual el poder no tiene frente a sí sino la más pura vida biológica, sin mediación alguna" (Agamben, 1998: 6).

En este sentido, Agamben señala que los campos de concentración no son privativos de los nazis y ni siquiera son ellos sus inventores ${ }^{3}$, ya que estaríamos en presencia de un campo cada vez que el estado de excepción se instituye como la norma y se configura un espacio en el que la vida desnuda está sola frente al soberano. Es todo espacio donde los hombres están a merced del puro arbitrio de los guardianes; todo aquel lugar en que hombres sin derechos quedan a merced de quienes fungen como soberanos en ese espacio (Saidel, 2006). En virtud de ello Agamben señala diversos espacios que pueden considerarse como campos:

Será un campo tanto el estadio de Bari, donde en 1991 la policía italiana hacinó provisoriamente a los inmigrantes clandestinos albaneses antes de devolverlos a su propio país, como el velódromo de invierno en el que la autoridad de Vichy acogió a los judíos antes de entregárselos a los alemanes; tanto el campo de prófugos en la zona fronteriza con España en el que murió preso en 1939 Antonio Machado, como las zonas de espera de los aeropuertos internacionales franceses en las que permanecían retenidos los extranjeros que pedían que se los reconociera con el estatuto de refugiados... Pero incluso

\footnotetext{
3 "Los historiadores discuten si la primera aparición de los campos debe identificarse con los «campos de concentración» creados por los españoles en Cuba en 1896 para reprimir las insurrecciones de la población de la colonia, o con la concentración en campos en los cuales los ingleses, a principios de siglo, hacinaron a los böers". (Agamben, 1998: 3)
} 


\section{SEe}

ciertas periferias de las grandes ciudades posindustriales comienzan hoy a asemejarse, en este sentido, a los campos, en donde la vida desnuda y la vida política entran, al menos en determinados momentos, en una zona de absoluta indeterminación (Agamben, 1998: 6 - 7).

Como se puede apreciar para Agamben el campo de concentración es el paradigma y matriz de la biopolítica moderna, ya que de manera progresiva y permanente se crean espacios de excepción en el que la ley se suspende totalmente; espacios en los que todos los moradores son nuda vida sujetos a merced del soberano. Y así como el campo se hace común en la vida moderna, entonces la víctima principal de los campos de concentración, el muselmann o aquel prisionero completamente abyecto que perdió toda disposición a resistir y es prácticamente un muerto en vida, es, dado que los campos se generalizan, el sujeto típico de la modernidad (Agamben, 2000).

\section{Proyecciones para el estudio del mundo contemporáneo}

A partir de los enfoques interpretativos de los autores citados se pueden analizar fenómenos importantes del mundo contemporáneo, caracterizado, según Hosbawm, por un aumento de la violencia política, la incapacidad de los Estados para mantener legítimamente el orden y por profundas dislocaciones sociales (Hobsbawm, 2007).

En dicho contexto las tesis de Agamben que presentan los campos de concentración como espacios donde todo derecho queda suspendido, haciendo del estado de excepción la norma y donde la vida queda completamente a merced de los soberanos, mantienen total vigencia para estudiar fenómenos como el nazismo, pero también todos los momentos de la historia contemporánea donde se han instaurado y se siguen instaurando campos de concentración (gulag soviético, cárceles de Pinochet, Franco, campos de la ex Yugoslavia, etc.).

En concordancia con ello la reflexión importante debe girar, a nuestro juicio, en torno a los factores sociales, políticos, económicos y culturales que determinan que los campos se repitan una y otra vez en la historia de las últimas décadas, pese a los avances habidos en materia de derechos humanos.

Dicha reflexión es fundamental para la historiografía y la sociología en el ámbito académico, pero no se limita a él, ya que la presencia misma del campo contraviene las bases éticas y jurídicas sobre las que se asienta el sistema democrático, por lo que estos problemas poseen también una clara dimensión práctica ya que el campo, al ser el espacio donde se produce la intervención más brutal sobre los cuerpos, constituye un problema vital para la convivencia democrática y, en este sentido, es importante reconocer por qué ya no solo son las dictaduras las que recurren al campo de concentración, sino que también estos se presentan en sociedades con sistemas democráticos consolidados. 


\section{SEe \\ scanesea}

Por su parte las ideas de Foucault presentan, a nuestro juicio, su mayor potencial explicativo al utilizarse para investigar los actuales procesos de medicalización que se presentan en la sociedad, dado que diversos problemas sociales como la obesidad, el alcoholismo, la depresión, la delincuencia, el rendimiento escolar, etc., son analizados a la luz del saber específico de la medicina y son psiquiatras, neurólogos y otros quienes aparecen como los únicos que saben del problema. Con ello se limitan las posibilidades de considerarlos como problemas derivados del funcionamiento social, ya que al ser problemas médicos, entonces se resuelven con métodos médicos y con ello se dejan de lado las determinaciones sociales del problema. Por ejemplo, si la depresión es solo un problema médico (tratable con fármacos), entonces no es necesario estudiar la correlación entre depresión y sistema laboral imperante; entre depresión y desarticulación de las redes sociales (atomización social); entre depresión y sobrevaloración del éxito económico. Asimismo, al medicalizar la obesidad, entonces no es necesario estudiar la posible relación entre aumento de la obesidad y aumento del consumismo en general; entre obesidad y extensas jornadas de trabajo; entre obesidad y disminución del tiempo que los hijos pasan con sus padres. Es decir, la medicalización clausura la investigación social y legitima la intervención, preferentemente farmacológica, sobre el cuerpo del enfermo, y de paso libera al sistema social de la responsabilidad de producir y reproducir dichos fenómenos.

Por todo lo anterior podemos afirmar que las ideas en torno al concepto de biopolítica poseen amplia aplicación en el mundo contemporáneo. En primer lugar, los planteamientos de Agamben sirven de guía para identificar espacios que se constituyan como campo en la sociedad actual y deben orientar la reflexión que esclarezca el porqué de la aparición del campo. Tarea teórica de gran magnitud. Pero al mismo tiempo conllevan una tarea política de no menor importancia, ya que si se ha de entender la democracia no solo en sus aspectos formales, es preciso combatir esta tendencia moderna a la reproducción del campo, lo que a su vez implica ser capaces de identificar la presencia del campo. Por ello la tarea teórica y la tarea política están estrechamente ligadas.

Lo mismo puede decirse respecto de las ideas desarrolladas por Foucault, ya que el concepto de medicalización permite identificar aquellos fenómenos problemáticos que el sistema social produce y reproduce, pero que son interpretados y tratados como problemas médicos, contribuyendo a legitimar, por esta vía, el orden social. Esta identificación de los fenómenos medicalizados puede contribuir a cuestionar los procesos de medicalización y centrarse en las reales determinaciones sociales de los fenómenos antes descritos. Dicho aporte teórico posee su correlato práctico al cambiar el foco temático, dejando de centrarse en el cuerpo del enfermo para dirigir la mirada y la acción al sistema social. 


\section{S\&e}

\section{Referencias Bibliográficas}

Agamben, Giorgio (2000). Lo que queda de Auschwitz. El archivo y el testigo. Homo Sacer III. Valencia: Ed. Pretextos.

Agamben, Giorgio (1998). “QQué es un campo?” Revista Artefacto. Pensamientos sobre la técnica. Buenos Aires, $\mathrm{n}^{\circ} 2$.

Berrío, Ayder (2010). La exclusión-inclusiva de la nuda vida en el modelo biopolítico de Giorgio Agamben: algunas reflexiones acerca de los puntos de encuentro entre democracia y totalitarismo. Recuperado de <http://www.scielo.unal.edu.co>

Castro, Edgardo (2007). “Biopolítica y Gubernamentalidad”, Revista Temas y Matices $\mathrm{n}^{\circ} 11$, primer semestre. Recuperado de <www.unioeste.br/saber>

Foucault, Michel (1987). Vigilar y Castigar. El nacimiento de la prisión. México: Siglo XXI Editores.

Foucault, Michel (1996). La vida de los hombres infames. La Plata: Ed. Altamira.

Foucault, Michel (1998). Historia de la Sexualidad I. La Voluntad de Saber. México: Siglo XXI editores.

Foucault, Michel (2006). Seguridad, Territorio y Población. Buenos Aires: FCE.

Foucault, Michel (2007). Nacimiento de la Biopolítica. Buenos Aires: FCE.

Hobsbawm, Eric (2007). Guerra y Paz en el siglo XXI. Barcelona: Ed. Crítica.

Múnera Ruiz y Benavides Venegas (2008). Normalidad y excepcionalidad en la política (Schmitt, Agamben, Žižek y Virno). Libros de google. <http: / /books.google.cl>

Saidel, Matías (2006). La Herencia Foucaultiana en el Abordaje de la Biopolítica de gamben y Esposito. Ponencia presentada en “Jornadas Foucault”, Universidad de San Martín, Buenos Aires. Recuperado de <http://www.biopolitica.cl/docs/publi_bio/saidel_herencia_foucaultiana.pdf> 
Rev. Sociedad \& Equidad № 3, Enero de 2012. Pp. 211-221

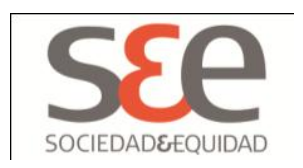

Salazar, Gabriel (2010). Conversaciones con Carlos Altamirano. Santiago: Ed. Random House S.A. 